\title{
Comparative Effectiveness of Long-Acting GLP-I Receptor Agonists in Type 2 Diabetes: A Short Review on the Emerging Data
}

This article was published in the following Dove Press journal: Diabetes, Metabolic Syndrome and Obesity: Targets and Therapy

\author{
Richard A Chudleigh' \\ Julia Platts ${ }^{2}$ \\ Stephen C Bain (1D $)^{1,3}$ \\ 'Singleton Hospital, Swansea Bay \\ University Health Board, Swansea, UK; \\ ${ }^{2}$ Diabetes Centre, University Hospital \\ Llandough, Cardiff and Vale University \\ Health Board, Cardiff, UK; ${ }^{3}$ Diabetes \\ Research Unit Cymru, Swansea \\ University Medical School, Swansea, UK
}

Correspondence: Richard A Chudleigh Email Richard.Chudleigh3@wales.nhs.uk

\begin{abstract}
Glucagon-like peptide-1 (GLP-1) receptor agonists have been available as glucose-lowering therapies for people with type 2 diabetes since 2006, when twice-daily exenatide was licenced. Since then, advances in peptide chemistry and delivery have allowed for once-daily and more recently once-weekly (QW) delivery of peptides in this class and there are currently three QW "long-acting" GLP-1 receptor agonists available in clinical practice. This short review describes the therapeutic landscape that is occupied by the modern type 2 diabetes glucose-lowering therapies with a particular focus on long-acting GLP-1 receptor agonists. The efficacy and side-effect profiles of the available QW GLP-1 receptor agonists are discussed, focusing on head-to-head clinical trial comparisons. There is also an appraisal of the cardiovascular outcome trials, for which there has been an assessment of each of the QW GLP-1 receptor agonists, leading to clinical conclusions regarding their comparative effectiveness.
\end{abstract}

Keywords: GLP-1, type 2 diabetes, cardiovascular trial

\section{Introduction}

The incidence of type 2 diabetes mellitus (T2D) continues to rise and it is estimated that $9 \%$ of the global adult population are affected by this condition. In the United Kingdom, $10 \%$ of healthcare spend is attributable to diabetes and in the most recent audit of National Health Service hospitals, $20 \%$ of in-patients have diabetes as a comorbidity. Attempts to reduce the burden of the "diabetes epidemic" by prevention have been universally unsuccessful, due to failure to reverse rising levels of obesity and sedentary lifestyle. This has led to a proliferation of pharmacologic therapies for hyperglycaemia and in the United States, there are now ten different classes of glucose-lowering medication.

Two of these drug classes, initially launched in the mid-2000s, impact on the incretin system. They stimulate the glucagon-like peptide 1 (GLP-1) receptor, which enhances insulin secretion and reduces the production of glucagon, both in a glucose-dependent manner. The dipeptidyl peptase-4 (DPP-4) inhibitors are oral agents, which enhance endogenous GLP-1 activity by reducing its degradation by the widely distributed enzyme DPP-4. Their mechanism of action means that they do not cause hypoglycaemia nor lead to weight gain. They have also been shown to be safe in large studies examining their potential to increase cardiovascular (CV) disease (a mandatory regulatory requirement for new glucose-lowering therapies). 
The second class of incretin agents are the GLP-1 receptor agonists (GLP-1RAs). These are injectable peptides which are resistant to DPP-4 degradation, providing supra-physiological stimulation of the GLP-1 receptor. GLP-1RAs also slow gastric emptying and, probably via an effect on the brain, increase satiety; both of these effects lead to weight loss in a substantial proportion of patients. They are, however, less well tolerated than DPP-4 inhibitors, with gastro-intestinal side-effects of nausea, vomiting and diarrhoea being common following initiation (although these diminish over time in most subjects).

The first GLP-1RA to be marketed (exenatide [Byetta ${ }^{\circledR}$ ]) was based on the exendin-4 molecule (isolated from the saliva of the Gila Monster lizard) and had to be administered twice daily with meals due to its short half-life. ${ }^{1}$ Subsequently launched GLP-1RAs were once-daily preparations (liraglutide $\left[\right.$ Victoza $\left.^{\circledR}\right]$ and lixisenatide $\left[\right.$ Lyxumia $\left.^{\circledR}\right]$ ) which could be administered without regard to meal times, ${ }^{2,3}$ in 2011 the European Medicines Agency issued marketing authorisation for a once-weekly (QW) version of exenatide [Bydureon ${ }^{\circledR}$ ], the first long-acting GLP-1RA. ${ }^{4}$

Exenatide extended release (ER) contains the exendin4 molecule interlinked with microspheres of poly-(D, L-lactide-co-glycolide) polymers, degradable material that had previously been used in absorbable sutures. The absorption of exenatide involves an initial phase of release for $48 \mathrm{hrs}$, then continued diffusion of exenatide for fourteen days; finally, there is release mediated by erosion for up to seven weeks. These pharmacokinetic features facilitate a continual release of drug without significant peaks and troughs in plasma concentration and allow for once weekly (QW) administration. Exenatide ER is prescribed as a powder and this needs to be suspended in aqueous solution immediately prior to injection; this has led to the development of various devices to aid suspension, some of which have involved vigorous shaking. There is also an issue of injection-site swelling due to the slow clearance of polymer, which can still be felt four weeks post-injection. Exenatide ER is administered as a single dose of $2 \mathrm{mg}$ QW with no need for slow up-titration.

The second long-acting GLP-1RA launched in 2014 was albiglutide $\left(\right.$ Eperzan $\left.^{\circledR}\right)$, closely followed by dulaglutide (Trulicity $\left.{ }^{\circledR}\right) .{ }^{5,6}$ Unlike exenatide, both of these GLP1RAs are analogues of the human GLP-1 molecule rather than exendin-4. Albiglutide is made up of multiple copies of a modified human glucagon-like peptide (amino acids 7-36) coupled to recombinant human albumin. After subcutaneous administration it appears to be absorbed via the lymphatic circulation with a maximum plasma concentration achieved around four days and with steady state after 4-5 weeks QW administration. Unfortunately, the administration of this medication is also complicated involving two periods of mixing separated by a 15-30 min wait, depending on the dose (30-50mg).

Dulaglutide is a recombinant DNA-produced polypeptide analogue of human GLP-1 (amino acids 7-37) which is covalently linked to each Fc arm of human immunoglobulin G4 (IgG4). This structure improves solubility and reduces immunogenicity, whilst also lowering renal clearance. As a result of the solubility, no shaking or mixing is required and the administration is very simple. Dulaglutide is administered in two doses $(0.75 \mathrm{mg}$ and $1.5 \mathrm{mg} \mathrm{QW})$ without the need for up-titration.

The most recently lunched long-acting GLP-1RA (2018) is semaglutide $\left(\mathrm{Ozempic}^{\circledR}\right){ }^{7}$ This molecule differs from human GLP-1 by two amino acids (94\% homology), one of which protects against DPP4 degradation. There is an 18 carbon fatty diacid chain attached via a spacer to the lysine amino acid at position 26 of the molecule, which provides strong binding to albumin, facilitating the prolongation of action. Semaglutide is delivered as a clear, colourless solution which does not require resuspension. It is initiated at a dose of $0.25 \mathrm{mg}$ QW titrated after one month to a maintenance dose of $0.5 \mathrm{mg}$ or, with further up-titration, $1.0 \mathrm{mg} \mathrm{QW}$.

As mentioned earlier, all new glucose-lowering therapies are subjected to cardiovascular outcome trials (CVOTs) and, as per the FDA mandate, the long-acting GLP-1RAs have been assessed against placebo. The CVOT for exenatide ER confirmed non-inferiority (i.e. cardiovascular safety) but did not show superiority for the primary end-point, which was a composite of major cardiovascular events (CV death, non-fatal myocardial infarction or non-fatal stroke, termed 3-P MACE). ${ }^{8}$ In contrast, the long-acting GLP-1 analogues (albiglutide, dulaglutide \& semaglutide) have not only been found to be safe but have also demonstrated $\mathrm{CV}$ benefit over placebo. $^{9-11}$ It is quite possible that this represents differences in the trial designs and, indeed, meta-analyses suggest no significant differences between medications in this class. ${ }^{12}$ However, the CVOT of lixisenatide, which is also exendin-4 based did not show CV superiority whilst the LEADER trial of liraglutide, a molecule closely analogous to semaglutide was positive. ${ }^{13,14}$

Unlike most classes of glucose-lowering therapies, some head-to-head comparisons of long-acting GLP-1RAs have been published, allowing some direct comparison of 
effectiveness. The SUSTAIN 3 trial compared the safety and efficacy of semaglutide 1.0mg QW with exenatide ER 2.0mg QW in a Phase 3a, open-label, randomised clinical trial. ${ }^{15} 813$ subjects with T2D already taking oral glucoselowering medications were randomised to active comparator therapy for 56 weeks with the primary end-point being change from baseline $\mathrm{HbA} 1 \mathrm{c}$.

The mean HbA1c (baseline 8.3\% [67.7 $\mathrm{mmol} / \mathrm{mol}]$ ) fell by $1.5 \%(16.8 \mathrm{mmol} / \mathrm{mol})$ in subjects receiving semaglutide and by $0.9 \%(10.0 \mathrm{mmol} / \mathrm{mol})$ with exenatide ER (estimated treatment difference [ETD] $-0.62 \%$ [95\% CI $-0.80,-0.44][-6.78 \mathrm{mmol} / \mathrm{mol}(95 \% \mathrm{CI}-8.70,-4.86)])$. This was statistically significant for both non-inferiority and superiority, in favour of semaglutide, and more patients receiving semaglutide (67\%) achieved an $\mathrm{HbAlc}$ $<7.0 \%$ ( $<53 \mathrm{mmol} / \mathrm{mol}$ ) versus $40 \%$ of those taking exenatide ER. The baseline bodyweight (mean of $95.8 \mathrm{~kg}$ ) was lowered by $5.6 \mathrm{~kg}$ (semaglutide) and $1.9 \mathrm{~kg}$ (exenatide ER) respectively, giving an ETD $-3.78 \mathrm{~kg}[95 \% \mathrm{CI}$ $-4.58,-2.98$ ] which was highly significant. The treatments both had similar safety profiles although gastrointestinal adverse events were more common with semaglutide (41.8\%) than with exenatide ER (33.3\%). Injection-site reactions were more frequently reported with exenatide ER $(22.0 \%)$ than with semaglutide $(1.2 \%)$.

The SUSTAIN 7 trial compared once-weekly semaglutide with dulaglutide in people with sub-optimally controlled T2D. ${ }^{16}$ This open-label, parallel-group, phase $3 \mathrm{~b}$ trial recruited patients aged 18 years or older who were on metformin monotherapy with an HbAlc between 7.0 $10.5 \%$ (53.0-91.0 $\mathrm{mmol} / \mathrm{mol})$. Patients were randomised to receive semaglutide $0.5 \mathrm{mg} \mathrm{QW}$, dulaglutide $0.75 \mathrm{mg}$ QW, semaglutide 1.0 mg QW or dulaglutide $1.5 \mathrm{mg}$ QW. The primary endpoint of SUSTAIN 7 was change in HbA1c from baseline; a secondary endpoint considered the change in bodyweight after 40 weeks treatment exposure. The trial was powered for HbAlc non-inferiority (set at a margin of $0.4 \%,[4.4 \mathrm{mmol} / \mathrm{mol}])$ and for bodyweight superiority.

A total of 1201 patients were randomised with similar numbers of participants $(\sim 300)$ in each of the four study arms and approximately $6 \%$ of patients withdrew from the study (43 receiving semaglutide and 29 receiving dulaglutide). The mean $\mathrm{HbAlc}$ was reduced by $1.5 \%(16.4 \mathrm{mmol} / \mathrm{mol})$ with $0.5 \mathrm{mg}$ semaglutide compared with $1.1 \%(12.1 \mathrm{mmol} / \mathrm{mol})$ with $0.75 \mathrm{mg}$ dulaglutide and this difference was statistically significant, in favour of semaglutide. Similarly, comparison of the higher doses of the two agents showed a significantly better reduction in $\mathrm{HbA} 1 \mathrm{c}$ for semaglutide (ETD $-0.41 \%$ [4.5mmol $/ \mathrm{mol}] ; \mathrm{p}<0.0001)$. For the secondary end-point of bodyweight, this was reduced by $4.6-6.5 \mathrm{Kg}$ for the two doses of semaglutide compared with $2.3-3.0 \mathrm{Kg}$ with dulaglutide; comparisons of the respective doses were highly significant, both favouring semaglutide.

As expected, gastrointestinal adverse events were frequently reported and occurred in, $43-44 \%$ of subjects receiving semaglutide compared with $33-48 \%$ with the two doses of dulaglutide. These side-effects were also the most common reason for discontinuing treatment in the trial.

Albiglutide has not been directly compared with either semaglutide or dulaglutide but was assessed versus oncedaily liraglutide in the HARMONY 7 trial. ${ }^{17}$ Comparison with liraglutide is of interest since this agent was also in a head-to-head comparison with once-weekly exenatide ER in the DURATION-6 trial, where liraglutide was seen to be superior to exenatide ER in terms of HbAlc lowering. ${ }^{18}$ HARMONY 7 was a 32-week, open-label, phase 3 trial which recruited 841 adults with suboptimally controlled T2D and BMI 20-45 kg/m². Subjects were randomised to receive albiglutide $30 \mathrm{mg} \mathrm{QW}$ titrated to $50 \mathrm{mg}$ at week 6, or liraglutide titrated to $1.8 \mathrm{mg}$ OD over a two week period. ${ }^{17}$ The primary endpoint was change in $\mathrm{HbAlc}$ from baseline for both albiglutide versus liraglutide, with a 95\% CI upper margin of $0.3 \%$ to show non-inferiority. 422 subjects were allocated to the albiglutide group and 419 to liraglutide and the change in $\mathrm{HbAlc}$ at week 32 was $-0.78 \%(8.6 \mathrm{mmol} / \mathrm{mol})$ in the albiglutide group and $-0.99 \%(10.9 \mathrm{mmol} / \mathrm{mol})$ in the liraglutide group. The treatment difference was $0.21 \%$ with confidence intervals $(0.08-0.34 \%)$ extending beyond $0.3 \%$ and so non-inferiority was not demonstrated, i.e. liraglutide showed superior glucose lowering to albiglutide. More patients given albiglutide experienced injection-site reactions compared to subjects who received liraglutide $(12.9 \%$ vs $5.4 \%$ ), whereas the opposite was seen for gastrointestinal adverse events, which occurred in $49.0 \%$ of patients in the liraglutide group versus $35.9 \%$ in the albiglutide group; both of these between-group differences were statistically significant.

The similar levels of difference in $\mathrm{HbA} 1 \mathrm{c}$ reduction for both exenatide ER (DURATION-6) and albiglutide (HARMONY 7) compared to liraglutide are consistent with an indirect comparison of the two studies using a Bucher analysis. $^{19}$ This showed a treatment difference of $0.0 \%$ in mean change in $\mathrm{HbAlc}$ from baseline, and that albiglutide $50 \mathrm{mg}$ was non-inferior to exenatide $2.0 \mathrm{mg} \mathrm{QW}$ at the noninferiority margin of $0.3 \%$. The effect of different agents on 
Table I Effect of Treatment on HbAlc and Body Weight

\begin{tabular}{|c|c|c|c|c|c|}
\hline Study & Drug & Dose & Frequency & HbA Ic Reduction Mean (SE) & Body Weight Change Mean (SE/SD) \\
\hline SUSTAIN $3^{15}$ & $\begin{array}{l}\text { Exenatide ER } \\
\text { Semaglutide }\end{array}$ & $\begin{array}{l}2 \mathrm{mg} \\
\mathrm{I} \mathrm{mg}\end{array}$ & $\begin{array}{l}\text { Weekly } \\
\text { Weekly }\end{array}$ & $\begin{array}{l}-0.9(0.06) \% \\
-1.5(0.06) \%\end{array}$ & $\begin{array}{l}-1.9(0.29) \mathrm{kg} \\
-5.6(0.29) \mathrm{kg}\end{array}$ \\
\hline SUSTAIN 7 (low dose) ${ }^{16}$ & $\begin{array}{l}\text { Dulaglutide } \\
\text { Semaglutide }\end{array}$ & $\begin{array}{l}0.75 \mathrm{mg} \\
0.5 \mathrm{mg}\end{array}$ & $\begin{array}{l}\text { Weekly } \\
\text { Weekly }\end{array}$ & $\begin{array}{l}-1.1(0.05) \% \\
-1.5(0.06) \%\end{array}$ & $\begin{array}{l}-2.3(0.27) \mathrm{kg} \\
-4.6(0.28) \mathrm{kg}\end{array}$ \\
\hline SUSTAIN 7 (high dose) ${ }^{16}$ & $\begin{array}{l}\text { Dulaglutide } \\
\text { Semaglutide }\end{array}$ & $\begin{array}{l}1.5 \mathrm{mg} \\
1.0 \mathrm{mg}\end{array}$ & $\begin{array}{l}\text { Weekly } \\
\text { Weekly }\end{array}$ & $\begin{array}{l}-1.4(0.06) \% \\
-1.8(0.06) \%\end{array}$ & $\begin{array}{l}-3.0(0.27) \mathrm{kg} \\
-6.5(0.28) \mathrm{kg}\end{array}$ \\
\hline HARMONY $7^{17}$ & $\begin{array}{l}\text { Albiglutide } \\
\text { Liraglutide }\end{array}$ & $\begin{array}{l}50 \mathrm{mg} \\
1.8 \mathrm{mg}\end{array}$ & $\begin{array}{l}\text { Weekly } \\
\text { Daily }\end{array}$ & $\begin{array}{l}-0.78 \% \\
-0.98 \%\end{array}$ & $\begin{array}{l}-0.6(3.12) \mathrm{kg} \\
-2.2(4.15) \mathrm{kg}\end{array}$ \\
\hline DURATION $6^{18}$ & $\begin{array}{l}\text { Exenatide ER } \\
\text { Liraglutide }\end{array}$ & $\begin{array}{l}2 \mathrm{mg} \\
1.8 \mathrm{mg}\end{array}$ & $\begin{array}{l}\text { Weekly } \\
\text { Daily }\end{array}$ & $\begin{array}{l}-1.28(0.05) \% \\
-1.48 \%(\mathbf{0 . 0 5}) \%\end{array}$ & $\begin{array}{l}-2.68(0.18) \mathrm{kg} \\
-3.57(0.18) \mathrm{kg}\end{array}$ \\
\hline
\end{tabular}

Note: Results in bold type represent significant benefit $(p<0.05)$ in outcome over the comparator drug.

$\mathrm{HbAlc}$ and body weight in the various studies reported here are summarised in Table 1.

Current licencing for GLP 1RAs recommends their use to improve glycaemic control alongside other glucoselowering medications including insulin. The 2018 joint ADA/EASD guidelines for the management of hyperglycaemia in patients with type 2 diabetes promote the use of GLP 1 RAs or SGLT2 $i$ as second-line therapy in those with Atherosclerotic cardiovascular disease (ASCVD), heart failure or renal impairment. ${ }^{20}$ The decision on which agent to recommend will largely be dictated by individual factors such as co-morbidity and renal function. However, there is interest in the use of GLP 1 RAs and SGLT2 $i$ in combination. Although evidence is scarce on the use of this combination, The DURATION 8 study demonstrated that the combination of Exenatide ER and Dapagliflozin resulted in greater improvements in glycaemic control, weight and systolic blood pressure than when either drug used alone. ${ }^{21}$ Similarly, the addition of Dulaglutide in patients already treated with SGLT2i and uncontrolled Diabetes produced additional reductions in HbA1c and greater weight loss versus placebo. ${ }^{22}$ It is speculated than the addition of a GLP 1 RA may reduce the higher glucagon levels seen with SGLT2i therapy.

\section{Conclusions}

In terms of HbA1c and weight, it appears that semaglutide is the most efficacious of the currently available longacting GLP-1RAs. Regarding side-effects, which are predominantly gastro-intestinal, these appear to be a class effect but with some relationship to glucose-lowering potency (more with semaglutide, less with albiglutide).
Increased diabetic retinopathy (DR) events seen with semaglutide in SUSTAIN 6 are thought to be related to rapid reduction in glucose levels in subjects with poor glycaemic control and existing retinopathy. ${ }^{1,23,24}$ It is of note that a non-significant increase in DR events was also seen in the CVOTs for both liraglutide and dulaglutide ${ }^{10,14}$ consistent with an impact of potent glucose-lowering. Other aspects will also impact on clinical decisionmaking, for example, the injection preparation (problematic for exenatide ER and albiglutide) as well as the design of administration device, which may favour dulaglutide. These tend to be reflected in quality of life assessments. $^{25}$ Finally, there is the issue of cost, which will obviously vary in different health care systems. Where the prices of the long-acting GLP-1RAs are equivalent, then health technology analyses are largely driven by HbA1c and weight and reflect differences in efficacy. ${ }^{26}$

\section{End note}

Albiglutide was globally withdrawn for commercial reasons in July 2018. However, the CVOT for albiglutide was subsequently published and demonstrated superiority and so it has been suggested that another pharmaceutical company may relaunch this product in the future and so it has been included in this review.

\section{Disclosure}

Dr Richard A Chudleigh reports personal fees from Novo Nordisk, Eli Lilly, Merck Sharpe \& Dohme, Boehringer Ingelheim, Astra Zeneca, Takeda, Napp., outside the submitted work. Professor Stephen Bain reports grants, personal fees, travel support to and registration at medical 
meetings from Novo Nordisk, Eli Lilly, Sanofi, and Astra Zeneca, outside the submitted work; and Professor Bain has given expert advice on this class of glucose-lowering agents to the National Institute for Health and Care Excellence (NICE) and the All-Wales Medicines Strategy Group. The authors report no other conflicts of interest in this work.

\section{References}

1. Available from: https://www.ema.europa.eu/en/medicines/human/ EPAR/byetta. Accessed February 3, 2020.

2. Available from: https://www.medicines.org.uk/emc/product/6585/ smpc. Accessed February 3, 2020.

3. Available from: https://www.ema.europa.eu/en/medicines/human/ EPAR/lyxumia. Accessed February 3, 2020.

4. Available from: https://www.ema.europa.eu/en/medicines/human/ EPAR/bydureon. Accessed February 3, 2020.

5. Available from: https://www.ema.europa.eu/en/medicines/human/ EPAR/eperzan. Accessed February 3, 2020.

6. Available from: https://www.ema.europa.eu/en/medicines/human/ EPAR/trulicity. Accessed February 3, 2020.

7. Available from: https://www.ema.europa.eu/en/medicines/human/ EPAR/ozempic. Accessed February 3, 2020.

8. Holman RR, Bethel MA, Mentz RJ, et al; EXSCEL Study Group. Effects of once-weekly exenatide on cardiovascular outcomes in type 2 diabetes. N Engl J Med. 2017;377(13):1228-1239. doi:10.1056/ NEJMoa1612917

9. Hernandez AF, Green JB, Janmohamed S, et al; Harmony Outcomes Committees and Investigators. Albiglutide and cardiovascular outcomes in patients with type 2 diabetes and cardiovascular disease (Harmony Outcomes): a double-blind, randomised placebo-controlled trial. Lancet. 2018;392(10157):1519-1529. doi:10.1016/S0140-6736 (18)32261-X

10. Gerstein HC, Colhoun HM, Dagenais GR, et al; REWIND Investigators. Dulaglutide and cardiovascular outcomes in type 2 diabetes (REWIND): a double-blind, randomised placebo-controlled trial. Lancet. 2019;394(10193):121-130. doi:10.1016/S0140-6736 (19)31149-3

11. Marso SP, Bain SC, Consoli A, et al; SUSTAIN-6 Investigators. Semaglutide and cardiovascular outcomes in patients with type 2 diabetes. $N$ Engl J Med. 2016;375(19):1834-1844. doi:10.1056/ NEJMoa1607141

12. Kristensen SL, Rørth R, Jhund PS, et al. Cardiovascular, mortality, and kidney outcomes with GLP-1 receptor agonists in patients with type 2 diabetes: a systematic review and meta-analysis of cardiovascular outcome trials. Lancet Diabetes Endocrinol. 2019;7 (10):776-785. doi:10.1016/S2213-8587(19)30249-9

13. Pfeffer MA, Claggett $B$, Diaz $R$, et al; ELIXA Investigators. Lixisenatide in patients with type 2 diabetes and acute coronary syndrome. N Engl J Med. 2015;373(23):2247-2257. doi:10.1056/ NEJMoa1509225

14. Marso SP, Daniels GH, Brown-Frandsen K, et al; LEADER Steering Committee; LEADER Trial Investigators. Liraglutide and cardiovascular outcomes in type 2 diabetes. $N$ Engl J Med. 2016;375 (4):311-322. doi:10.1056/NEJMoa1603827
15. Ahmann AJ, Capehorn M, Charpentier G, et al. Efficacy and safety of once-weekly semaglutide versus exenatide ER in subjects with type 2 diabetes (SUSTAIN 3): a 56-week, open-label, randomized clinical trial. Diabetes Care. 2018;41(2):258-266. doi:10.2337/dc17-0417

16. Pratley RE, Aroda VR, Lingvay I, et al; SUSTAIN 7 Investigators. Semaglutide versus dulaglutide once weekly in patients with type 2 diabetes (SUSTAIN 7): a randomised, open-label, phase 3b trial. Lancet Diabetes Endocrinol. 2018;6(4):275-286. doi:10.1016/ S2213-8587(18)30024-X

17. Pratley RE, Nauck MA, Barnett AH, et al; HARMONY 7 Study Group. Once-weekly albiglutide versus once-daily liraglutide in patients with type 2 diabetes inadequately controlled on oral drugs (HARMONY 7): a randomised, open-label, multicentre, non-inferiority phase 3 study. Lancet Diabetes Endocrinol. 2014;2 (4):289-297. doi:10.1016/S2213-8587(13)70214-6

18. Buse JB1, Nauck M, Forst T, et al. Exenatide once weekly versus liraglutide once daily in patients with type 2 diabetes (DURATION-6): a randomised, open-label study. Lancet. 2013;381 (9861):117-124. doi:10.1016/S0140-6736(12)61267-7

19. Martin AA, Parks D. An indirect comparison of HbAlc treatment effect with albiglutide and exenatide $2.0 \mathrm{mg}$ QW using the Bucher method. Diabetes Metab Syndr Obes. 2016;9:163-168. doi:10.2147/ DMSO.S100775

20. Davies MJ, D’Alession DA, Fradkin J, et al. Management of hyperglycaemia in type 2 diabetes, 2018. A consensus report by the American Diabetes Association (ADA) and the European Association for the Study of Diabetes (EASD). Diabetes Care. 2018;41(12):2669-2701. doi:10.2337/dci18-0033

21. Frias JP, Guja C, Hardy E, et al. Exenatide once weekly plus dapagliflozin once daily versus exenatide or dapagliflozin alone in patients with type 2 diabetes inadequately controlled with metformin monotherapy (DURATION-8): a 28 week, multicentre, double-blind, phase 3, randomised controlled trial. Lancet Diabetes Endocrinol. 2016; 4:1004-1016.

22. Ludvik B, Frias JP, Tinahones FJ, et al. Dulaglutide as add-on therapy to SGLT2inhibitors in patients with inadequately controlled type 2 diabetes (AWARD-10): a 24-week, randomised, double-blind, placebo-controlled trial. Lancet Diabetes Endocrinol. 2018;6 (5):370-381. doi:10.1016/S2213-8587(18)30023-8

23. Vilsbøll T, Bain SC, Leiter LA, et al. Semaglutide, reduction in glycated haemoglobin and the risk of diabetic retinopathy. Diabetes Obes Metab. 2018;20(4):889-897. doi:10.1111/dom.13172

24. Bain SC, Klufas MA, Ho A, Matthews DR. Worsening of diabetic retinopathy with rapid improvement in systemic glucose control: a review. Diabetes Obes Metab. 2019;21(3):454-466. doi:10.1111/ dom. 13538

25. Boye KS, Matza LS, Stewart KD, et al. Patient preferences and health state utilities associated with dulaglutide and semaglutide injection devices among patients with type 2 diabetes in Italy. $J$ Med Econ. 2019;22(8):806-813. doi:10.1080/13696998.2019.16 09482

26. Viljoen A, Hoxer CS, Johansen P, Malkin S, Hunt B, Bain SC. Evaluation of the long-term cost-effectiveness of once-weekly semaglutide versus dulaglutide for treatment of type 2 diabetes mellitus in the UK. Diabetes Obes Metab. 2019;21(3):611-621. doi:10.1111/ dom. 13564 


\section{Publish your work in this journal}

Diabetes, Metabolic Syndrome and Obesity: Targets and Therapy is an international, peer-reviewed open-access journal committed to the rapid publication of the latest laboratory and clinical findings in the fields of diabetes, metabolic syndrome and obesity research. Original research, review, case reports, hypothesis formation, expert opinion and commentaries are all considered for publication. The manuscript management system is completely online and includes a very quick and fair peer-review system, which is all easy to use. Visit http://www.dovepress.com/testimonials.php to read real quotes from published authors.

Submit your manuscript here: https://www.dovepress.com/diabetes-metabolic-syndrome-and-obesity-targets-and-therapy-journal 